\title{
Analysis of Need Development of Blended Learning Model Based Nine Event Instructional
}

\author{
Sudarman1, Sugeng ${ }^{2}$ \\ ${ }^{1}$ Department of Economic Education, Faculty of Teacher Training and Education, Mulawarman University, Indonesia \\ ${ }^{2}$ Department of Mathematic Education, Faculty of Teacher Training and Education, Mulawarman University, Indonesia \\ daremantep@gmail.com,kenduk_s@yahoo.com
}

\begin{abstract}
The purpose of this research is (1) to describe the design of Blended Learning model based on Nine Event Instructional, and (2) to analyze the need of the design of Blended Learning model based on Nine Event Instructional in the Research Methodology lecture. This research uses descriptivequalitative type involving samples of FKIP students in Mulawarman University, from 14 courses with Proportional cluster random sampling technique. The research data were collected through 3 questioner-shaped instruments, namely (1) VAK learning style, involving 340 students; (2) KOLB learning style, involving 426 students; and (3) FKIP learning model involving 359 students. The first and second instruments were tested for validity and reliability with the help of SPSS, while the third instrument tested the validity of the contents. Data analysis was done descriptively. Based on the analysis of the research data, (1) the description of the Blended Learning model design based on Nine Event Instructional, and (2) the needs analysis related to the blended learning design are (a) the lectures from the majority of students through the planning, implementation and evaluation stages; small lecturers have implemented blended learning design, i.e. face-to-face, offline, and online. In addition, only a few of 14 programs in FKIP Unmul already use internetbased ICT tools to the maximum, even tend to under $51 \%$.
\end{abstract}

Keywords—blended learning; nine even instructional; ict

\section{INTRODUCTION}

Improving the quality of learning is done by selecting, establishing, and developing optimal learning methods to achieve the desired results [1]. One of the efforts to improve the quality is through the development of learning design. However, to realize it needs to be studied the tendency of future learning related to the strategy and content of learning. The tendency of learning strategies has changed the traditional learning approach to today's learning (digital era) of learning can be done anywhere, meaning that students can study in the classroom, in the library, at home; anytime, not as school has scheduled, it can be in the morning, afternoon or evening; with whom, the student obtains learning resources through lecturers, other lecturers, experts, practitioners or the public; through anything, students can learn via the internet, CD ROM, radio, television, laboratories, and hands-on experience. The content and learning outcomes relate to the students' ability to understand the concepts and procedures of the studied disciplines. However, the reality shows that most of the learning in universities is still implemented in a classical manner. This means that teachers (lecturers) provide explanations to some students orally and face to face. In the learning process many aspects must be taken into account, including stimulants in the ability of thought processes, the growth of critical attitude, and able to change the views of the students who not only transfer of knowledge but also must be followed by the transfer of skills. This problem can be solved as the technology develops faster. The problem can be solved by designing a learning model that combines technological progress and improved learning quality, so that rapid technological advances can have an effect on the changing world of education and learning; In addition, learning technology always adopts and adapts the latest findings in the learning process [2], i.e. learning by Blended Learning model [3-5] based Nine Event Instructional. In learning in higher education, blended learning consists of face-to-face classroom meetings once per week, with students using online learning to complete group projects and other class assignments [6].

In the learning process, this learning strategy is used on the basis of (1) enriching the management of learning, (2) knowledge access, (3) social interaction, (4) personal agency, (5) cost effectiveness, and (6) ease of revision [3], and exploration of content management strategy, strategy of presentation and management strategy $[1,7]$ means that blended learning is a strategy to take advantage of the advantages of both learning modes (conventional and face-toface) computer, both online [8] and offline through e-learning $[3,9]$. Therefore, the combination of learning mode (online and conventional) that offer more effective learning and facilitate access to learning [3,10] states that "blended learning is a mixture of the various learning strategies and delivery methods that will optimize the learning experience of the user" The designs that need to be prepared in blended learning include content (content of learning materials), communication (communication between students and students), and construction [11]. Meaning, blended learning is a mixture of various learning strategies and delivery methods that optimize the learning experience for its users, and includes content, communication, and construction.

The design of learning as a process to determine what learning method is best implemented to arise changes in knowledge and skills in the students in the desired direction [7]. The design of learning that leads to future learning, one of which is the blended learning model. Blended learning model 
is basically a combination of learning face to face and virtually. Although the notion of blended learning has been accepted and used extensively by corporate training practitioners [3] and designers of learning, but the standard definition of blended learning does not yet exist. [12] provides the definition of blended learning as a combination of various pedagogical or teaching approaches such as collaborative learning with the support of tutors or conventional classroom teaching. Blended learning often refers specifically to the provision and use of learning resources that incorporate e-learning and other learning resources. $[5,8,10]$ expressed blended learning as an integrated combination of conventional learning approaches with page-based online learning, a combination of media and learning tools and a combination of approaches pedagogical, regardless of the learning technology used in each case.

TABLE I. LEARNING MODEL STEPS BASED ON INSTRUCTIONAL NINE EVENTS

\begin{tabular}{|c|c|c|}
\hline Stage & Learning Steps & Nine Event Instructional \\
\hline 1 & Submission of information & \begin{tabular}{|l} 
Draw attention \\
Inform the learning objectives \\
Stimulate memory \\
Present teaching materials
\end{tabular} \\
\hline 2 & Student guidance & Provide tutoring \\
\hline 3 & Practice & $\begin{array}{l}\text { Encourage performance } \\
\text { Provide informative feedback }\end{array}$ \\
\hline 4 & Assessment of learning & $\begin{array}{l}\text { Assess performance } \\
\text { Improve retention and transfer of } \\
\text { learning }\end{array}$ \\
\hline
\end{tabular}

TABLE II. BLENDED LEARNING DIMENSIONS

\begin{tabular}{|l|l|}
\hline $\begin{array}{l}\text { Dimensions } \\
\text { Presentation } \\
\text { mode }\end{array}$ & $\begin{array}{l}\text { A combination of conventional learning with page-based } \\
\text { online learning }\end{array}$ \\
\hline Technology & A combination of various media and technology devices \\
\hline Pedagogy & A combination of different pedagogical approaches \\
\hline Chronology & Synchronous and asynchronous apparatus \\
\hline
\end{tabular}

Thus, blended learning design is an integrated combination design of a combination of media approach and learning tools. The instructional model based on instructional nine event instruction is shown in Table I. Blended Learning has a commonly used dimension $[5,10]$ as shown in Table II. The implementation of learning blended learning requires supporting skills such as from lecturer's perspective. This blended learning strategy requires new skills so that students can absorb the knowledge of the lectures given, so that more students have the opportunity to develop themselves and take responsibility for themselves, improve their social competence, and information-gathering and achievement skills [13].

\section{RESEARCH METHODS}

This research was conducted at FKIP Mulawarman University, with a number of students coming from the entire study program. In the data collection, Lee and Owens suggested several techniques, including by phone, direct interview, via e-mail, paper questionnaire, video recording, and observation.

This study uses (1) VAK Learning Style Tool, (2) KOLB Learning Style Instrument, and (3) FKIP learning model. VAK learning style instrument (Visual, Auditory, and Kinesthetic) in the form of a questionnaire that refers to the Learning Styles Self-Assessment Questionnaire; consists of 30 items and each item consists of 3 options.

KOLB Learning style instrument in questionnaire form which refers to KLSI (The Kolb Learning Style Inventory) [14]. This instrument consists of 12 grain aspects and each grain aspect consists of 4 items of statement, the four options must be responded by the respondent, so that the instrument there are 48 items. The quantification of the optional scores from each of the Kolb statements is 1, 2, 3, and 4. The respondent determines the scoring weight to be loaded one by one from the four consecutively provided options $1,2,3$, and 4 .

The FKIP Model Learning Instrument in the form of a questionnaire consists of 10 items of statement, consisting of 9 questions and each statement provided with several options, and 1 item (description). Items 2 through 8 are provided with 4 options, point 1 with 2 options and for item 9 broken down into 6 sub questions with each of 4 options.

\section{A. Testing Validity and Reliability}

Testing instrument validity of VAK Learning Style using Product Moment correlation that is between each instrument item with its total score; with the help of the SPSS program. The test results indicate that there are 28 items of the instrument that are validly validated, i.e. the items having statistical significance (Sig.) Are smaller than the significance level $(\square)$; and there are 2 items of the instrument categorized invalid. The result of reliability test of Learning VAK style instrument (30 items) with the help of SPSS program showed Alpha reliability coefficient value of 0.483 (including medium category).

KOLB learning style instrument consists of 12 aspects and each aspect consists of 4 items. Thus, the instrument has 48 items. Testing the validity of KOLB Learning Instrument item using Product Moment correlation. The testing process is done with the help of SPSS program.

The test results show that the whole item (48 items) of KOLB style learning instrument is categorized as valid, each item has a statistical significance (Sig.) Smaller than the significance level $(\square)$. Therefore, the overall (48 point) learning style of KOLB already meets the requirements of validity. The result of instrument reliability test of Kolb Learning Style (48 items) with the help of SPSS program shows the value of Alpha reliability coefficient of 0.703 (including medium category).

\section{B. Research design}

The design of the development of the Nine Event Instructional based Blended Learning model uses the [15] learning strategy, which is (1) attracts attention, (2) informs the learning objectives, (3) stimulates the memory, (4) presents the teaching materials, (5) tutoring, (6) encouraging performance, (7) giving informative feedback, (8) assessing performance, and (9) enhancing retention and transfer of learning. The results of the use of strategy as the basis for developing the product of learning design model, printed materials, audio 
teaching materials, audio visual teaching materials, video teaching materials, interactive multimedia teaching materials, teaching materials and smart phone devices is published in WEB More specifically the development plan for developing multimedia using Lee and Owens development model (2004). This multimedia development model is a flexible model that can be tailored to the needs of the developer, with a path like Fig. 1.

\section{RESULTS AND DISCUSSION}

\section{A. Stage Analysis / assessment}

In the needs of analysis, there are six steps: (1) analyzing the existing conditions, like finding the root causes of the needs to be solved, (2) identifying what needs to be mastered (knowledge, attitude and skills) a task that should be completed, or the expected conditions, (3) based on step 2, then formulated objectives that have been identified are arranged in order of importance, (4) identifying the difference between the expected condition objectives and the conditions, (5) determining and documenting existing advantages related to performance, and (6) determining what is prioritized in addressing existing issues.

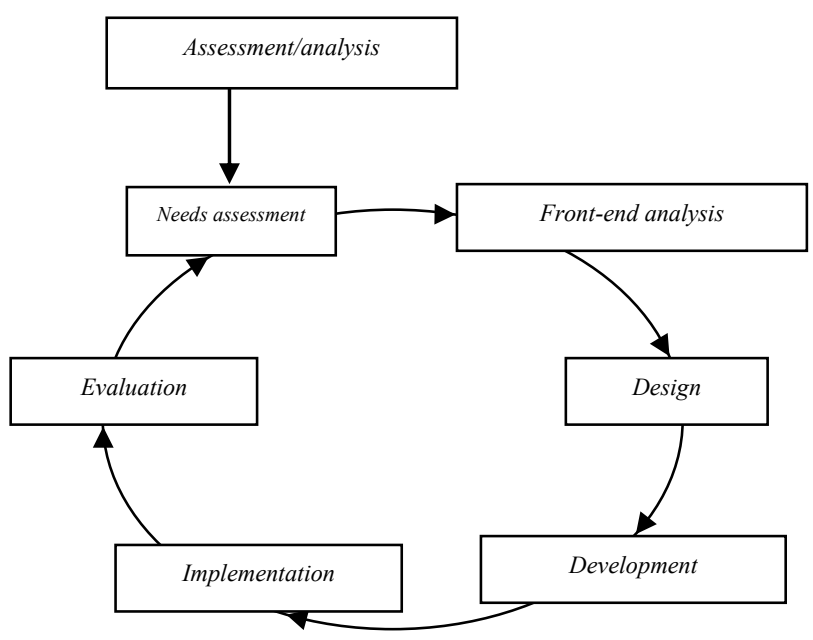

Fig. 1. Lee and Owens Multimedia Development Model

In the implementation of classroom learning, there are various student reactions, including: (a) good, (b) most actively asking, (c) enthusiastic and diligent; i.e. they show liveliness in the learning process; (d) feeling somewhat boring, because lectures Research methodology begins with basic theories of research; and (e) students are very reactive in following the course of learning, this is indicated by the interaction between lecturers and students through question and answer. The diversity of student reactions suggests a sense of pride in the learning practices for this course.

In the lecture of Research Methodology, student learning outcomes from various study programs show (a) Good, with an average score of \pm 80 ; and (b) Range values 70 - 92; as well as in Physics and Biology studies show the results achieved quite well. Especially in Mathematics Study Program, the understanding of research methodology concept is quite good and good category, although there are still some small students who do not understand. Learning outcomes related to procedural understanding of research methodology, lecturer of course lecturer revealed that students majoring in PMIPA are able to apply in the form of research proposal (thesis) with good enough, even in the study program of Math students able to present the results of preparation of proposal (proposal thesis) individually in front of class.

Alternative media that can be easier for students in lecturing process Research methodology in PMIPA majors are (a) LCD, (b) Power point program (PPt), (c) Photos, and (d) Video about research. The use of LCD media tend to be used frequently, because in every classroom in FKIP already installed the media in question.

Learning resources that support learning process activities (Face to face) especially lectures Methodology Research, (A) Textbook of research methodology (b) Diktat, (c) Hand out, (d) Journal of research (journals related to the learning process (f) Materials / materials / writings from the internet, (g) Modules, (h) Worksheets, and (i) guidelines for writing thesis / proposal. The most commonly used trends are Textbook Research Methodology and Research Journal.

The concrete steps that have been done by the lecturers of the MP subjects when they see the activity, motivation, and interest of the low student in following the tutoring are (a) Varying the learning strategy, (b) Providing individual duty to make the research plan (proposal) and (c) Displaying research videos whose results bring significant benefits, for example to make the students more interested, (d) to provide tasks by themselves and discussed in front of the class, and (e) Provide rewards for students who has done a good job in place of quiz I or quiz II.

The lecturers tend not to understand and apply the learning with blended learning model, which is the combination of faceto-face, offline, and online learning, and only the lecturers in the study program who have understood and applied them in the learning process. Lecturers in the Mathematics Study Program who already understand and apply them in the learning with the following composition: Face to face $50 \%$, Offline (interactive multimedia) $10 \%$, and Online (web based) $10 \%$, while the remaining $30 \%$ is used for presentation task research proposal.

With regard to the personal facilities that support learning activities, most $95 \%$ of respondents already own a smartphone as a means of communication, although the smartphone has not functioned as a learning tool, however this is a good start to move towards m-learning based learning (mobile learning). Similarly, laptop ownership for teachers is sufficient, which is $90 \%$, this is the capital for computer-based learning and can access a more diverse learning resources.

In the analysis phase, the characteristics of the students are analyzed the initial ability and the characteristics of the students. Early student skills are the foundation for the designer to determine the starting point of learning. Student analysis includes student learning style on learning modalities aspect by using VAK analysis, while cognitive style using learning style analysis developed by KOLB. 
The Result of Descriptive Analysis of VAK Learning Style Data is shown in Fig. 2.

\section{Learning Style VAK}

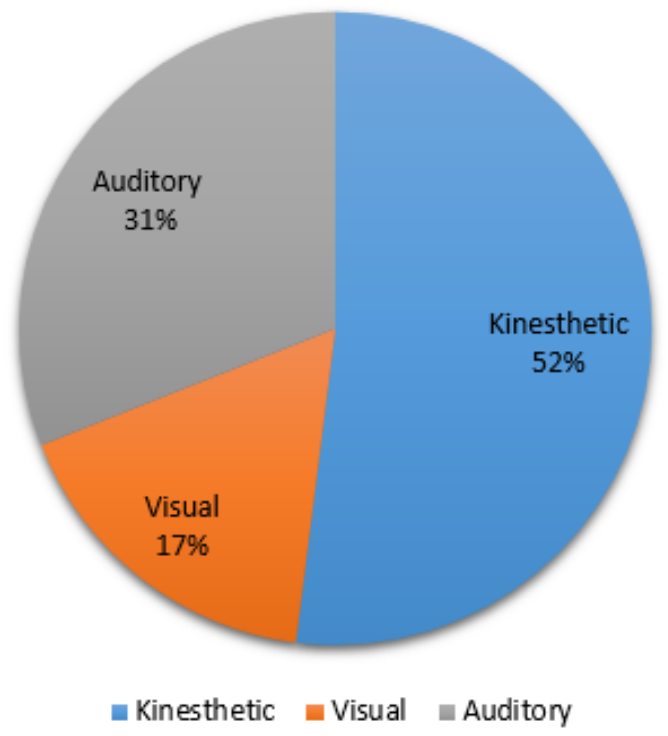

Fig. 2. Learning Styles of VAK by Faculty Level

Figure 2, it appears that Kinesthetic Learning Style is the most popular learning style by FKIP students $(52 \%)$. That is, half more than the number of study respondents tend to use kinesthetic learning style. Such conditions will have an impact on the implementation of learning (lectures) in general in FKIP. The preparation of RPS and learning tools will tend to lead to kinesthetic learning. However, not all lectures fit into kinesthetic learning. This condition is seen with $31 \%$ of respondents feel more suitable if learning using auditory style and $17 \%$ style with visual learning style.

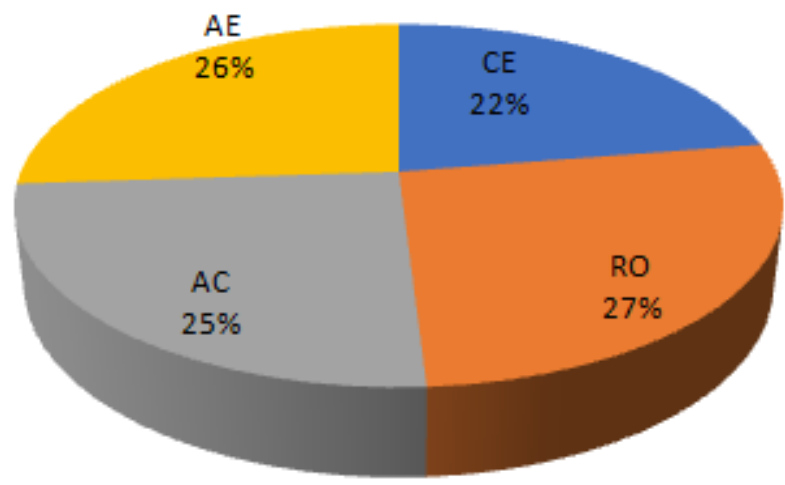

Fig. 3. The percentage of learning styles of KOLB

Figure 3, the results of descriptive analysis of Learning Styles by Kolb can be classified into four main trends, which is:
Concrete Experience (CE, 22\% of students learn through feelings, by emphasizing the aspects of concrete experience, more concerned with relationships with others and sensitivity to the feelings of others. Students engage themselves entirely through new experiences, and tend to be more open and adaptable to the changes they face.

Abstract Conceptualization (AC), 25\% of students learn through thinking and focus more on the logical analysis of ideas, systematic planning, and intellectual understanding of the situation or problem faced. Students create concepts that integrate their observations into sound theories, relying on systematic planning.

Reflective Observation (RO), 27\% of students study through observation (watching), emphasizing observing before judging, listening to a case from various perspectives, and always listening to the meaning of the things observed. Students will use their thoughts and feelings to form opinions, observe and reflect on various experiences.

Active Experimentation (AE), 26\% of students learn through action, tend to be strong in terms of ability to carry out the task, dare to take risks, and influence others through his actions. Students will appreciate their success in completing work, influencing others, and using theories to solve problems and make decisions.

In the implementation of learning, a small number of FKIP lecturers using RPP (respondents $10.3 \%$ of students), a small part also FKIP lecturers provide complete RPP (100\%, and $1.4 \%$ student response). With regard to RPP components, some lecturers who make up the RPP cover the whole component, as the students $(13.1 \%)$ stated that the lecturer only composed the component of the name of the course. With regard to the percentage of face-to-face, only some lecturers held face-toface 1005 (response of $3.06 \%$ of students), some lecturers held $75 \%-100 \%$ face to face (13.65\% student response). With regard to the assignment, as much as $1.9 \%$ stated that the lecturers always give the task (100\%); but there are $3.62 \%$ of students stated that under $50 \%$ of lecturers who give the task.

With regard to the development of teaching materials, only $5.01 \%$ of students stated that lecturers had developed teaching materials up to $100 \%$; but $38.16 \%$ of students say $51 \%-75 \%$, $75 \%-100 \%$ of lecturers do the preparation of teaching materials though not complete. Means, only a small part in the view of students, lecturers compile teaching materials to completion. A small number of lecturers, in learning using WEB facilities (response 5.01\% students); some students (37.88\%) say $51 \%-75 \%$ of lecturers make it, although not yet complete. With regard to learning in the present and future, according to $10.03 \%$ of students, $100 \%$ of lecturers play a very important role; and $6.41 \%$ of students stated below $50 \%$ of lecturers who play a role in it.

With regard to the presentation of learning materials contained in printed media, $45.4 \%$ of students stated that 75 $100 \%$ of lecturers tended to use it, but 37 or $10.3 \%$ of them stated that under $50 \%$ of lecturers used it. For the presentation of learning materials contained in the audio media, only $2.79 \%$ of students say lecturers always use audio, even $36.5 \%$ of students say under $50 \%$ of lecturers who wear them. In video 
use when learning presentation, $6.4 \%$ of students stated $100 \%$ of lecturers use it, and they tend to reveal that $51-100 \%$ are wearing it. In addition, as many as $16.16 \%$ of students stated that $100 \%$ of lecturers use computers, but $7.24 \%$ revealed that under $50 \%$ of lecturers are using it. Likewise in internet usage, about $22.84 \%$ say lecturers always use it, and only $6.96 \%$ of those who say under $50 \%$ of lecturers use computers. The use of hand to the presentation of the material of $12.81 \%$ which states that the lecturers use it, but $18.1 \%$ say below $50 \%$. Lecturers use it.

\section{CONCLUSION}

Blended Learning model based on instructional nine event is a learning model that combines face to face learning, offline, and online. Face to face learning tends to be widely practiced in learning (lectures). This type of learning is a conventionally categorized learning. Online learning focuses on the use of internet facilities.

\section{REFERENCES}

[1] I. N. S. Degeng. (1991). Landasan Teoritik Disain Pembelajaran.

[2] Sudarman, "Pengaruh Strategi Pembelajaran Blended Learning terhadap Perolehan Belajar Konsep dan Prosedur pada Mahasiswa yang Memiliki Self-Regulated Learning Berbeda," Doctoral, Pendidikan Pascasarjana Universitas Negeri Malang, 2013.

[3] C. Graham, "Blended learning systems: Definition, current trends, and future directions," in The handbook of blended learning: Global perspectives, local designs, ed, 2006, pp. 3-21.

[4] A. Heinze and C. Procter. (2010, The significance of the reflective practitioner in blended learning. 2-13.
[5] L. N. Alla, "Blended Learning vs Traditional Learning: What Works? (A Case Study Research)," in THE XXVI ANNUAL INTERNATIONAL ACADEMIC CONFERENCE, LANGUAGE AND CULTURE, 27-30 October 2015, 2015, pp. $77-82$.

[6] M. Molenda and E. Boling, "Creating," in Educational technology: A definition with commentary, ed: New York:Routledge., 2008, pp. 82130.

[7] C. M. Reigeluth, "Instructional-Design Theories and Models: An Overview of Their Current Status," ed: Hillsdale, NJ: Lawrence Erlbaum Associates., 1983

[8] V. Nikolaos, G. Maria, D. Vassiliki, M. Maria, and K. Efthimis, "The impact of blended and traditional instruction in students' performance," in INSODE 2011, 2012, pp. 1-5.

[9] L. W. Anderson and D. R. Krathwohl. (2001). A Taxonomy for Learning, Teaching, and Assessing: A revision of Bloom's Taxonomy of Educational Objectives.

[10] S.-E. Ling and A. M. Magdaline, "Blended Learning in Teaching Secondary Schools' English: A Preparation for Tertiary Science Education in Malaysia," presented at the IOSTE BORNEO 2014, 2015.

[11] M. Kerres and C. DeWitt, "A Didactical Framework for The Design of Blended Learning Arrangements," Journal of Educational Media, vol. 28 (2-3), pp. 101-113, 2003.

[12] S. Trapp, "Blended Learning Concepts - a Short Overview," in First European Conference on Technology Enhanced Learning, 2006.

[13] M. Kendall, "Teaching Online to Campus-Based Students: The Experience of Using Web CT for The Community Information Module at Manchester Metropolitan University," Education for Information, vol. 19(4), pp. 325-346, 2001.

[14] Y. K. Alice and A. K. David. (2013). THE KOLB LEARNING STYLE INVENTORY- Version 4.0 A Comprehensive Guide to the Theory, sychometrics, Research on Validity and Educational Applications. Available: www.learningfromexperience.com

[15] R. M. Gagne. (1983). The Conditions of Learning. 